\title{
Coordinated observation of field line resonance in the mid-tail
}

\author{
Y. Zheng ${ }^{1}$, A. T. Y. Lui ${ }^{1}$, I. R. Mann ${ }^{2}$, K. Takahashi ${ }^{1}$, J. Watermann ${ }^{3}$, S.-H. Chen ${ }^{4}$, I. J. Rae ${ }^{2}$, T. Mukai ${ }^{5}$, \\ C. T. Russell ${ }^{6}$, A. Balogh ${ }^{7}$, R. F. Pfaff ${ }^{8}$, and H. Rème ${ }^{9}$ \\ ${ }^{1}$ JHU/APL, Laurel, MD 20723-6099, USA \\ ${ }^{2}$ Space Physics Group, Department of Physics, University of Alberta, Edmonton, Alberta, Canada \\ ${ }^{3}$ Atmosphere Space Research Division, Danish Meteorological Institute, Denmark \\ ${ }^{4}$ Universities Space Research Association, NASA Goddard Space Flight Center, Greenbelt, MD, USA \\ ${ }^{5}$ ISAS/JAXA, 3-1-1, Yoshinodai, Sagamihara, Kanagawa 229-8510, Japan \\ ${ }^{6}$ Institute of Geophysics and Planetary Physics /UCLA, Los Angeles CA 90024-1567, USA \\ ${ }^{7}$ Imperial College, Department of Space and Atmospheric Physics, London, UK \\ ${ }^{8}$ Laboratory for Solar and Space Physics, NASA Goddard Space Flight Center, Greenbelt, MD 20771, USA \\ ${ }^{9}$ CESR, BP4346, 31028 Toulouse Cedex 4, Toulouse, France
}

Received: 28 October 2005 - Revised: 1 February 2006 - Accepted: 2 February 2006 - Published: 23 March 2006

\begin{abstract}
Standing Alfvén waves of $1.1 \mathrm{mHz}(\sim 15 \mathrm{~min}$ in period) were observed by the Cluster satellites in the mid-tail during 06:00-07:00 UT on 8 August 2003. Pulsations with the same frequency were also observed at several ground stations near Cluster's footpoint. The standing wave properties were determined from the electric and magnetic field measurements of Cluster. Data from the ground magnetometers indicated a latitudinal amplitude and phase structure consistent with the driven field line resonance (FLR) at $1.1 \mathrm{mHz}$. Simultaneously, quasi-periodic oscillations at different frequencies were observed in the post-midnight/early morning sector by GOES $12\left(l_{0} \approx 8.7\right)$, Polar $\left(l_{0} \approx 11-14\right)$ and Geotail $\left(l_{0} \approx 9.8\right)$. The 8 August 2003 event yields rare and interesting datasets. It provides, for the first time, coordinated in situ and ground-based observations of a very low frequency FLR in the mid-tail on stretched field lines.
\end{abstract}

Keywords. Magnetospheric physics (Magnetotail; MHD waves and instabilities; Plasma waves and instabilities; Solar wind-magnetosphere interactions)

\section{Introduction}

Research on field-line resonance (FLR) has a long and rich history from theoretical, observational and numerical simulation perspectives. In 1954, Dungey (1954) considered the possibility that ultra-low frequency (ULF) waves might constitute standing Alfvén waves along geomagnetic field lines. Samson et al. (1971) reported the first observational evidence

Correspondence to: Y. Zheng

(yihua.zheng@jhuapl.edu) of FLR and found the local amplitude maximum and polarization change across the resonance. Chen and Hasegawa (1974) and Southwood (1974) both independently provided a theoretical description on how compressional MHD waves couple to shear Alfvén waves, giving rise to FLRs. By the 1980s, the concept of a cavity mode wave was introduced by Kivelson and Southwood $(1985 ; 1986)$ to explain the quantization of compressional wave spectrum. More theoretical work was carried out using different geometries during the same decade (e.g. Allan et al., 1986; Lee and Lysak, 1989) as different geometries (boundary conditions) allow different wave mode structures. Theories on FLR were further developed and refined during the 1990s, as seen in the proposal of waveguide mode (Samson et al., 1992a), numerical studies including non-linear effects (e.g. Rankin et al., 1993), twofluid studies (e.g. Streltsov and Lotko, 1996), waveguide excitation by magnetosheath flows (e.g. Mann et al., 1999), tail waveguide theory (e.g. Allan and Wright, 1998) and so on. There have also been numerous FLR studies based on observations that either use ground data or satellite measurements or all the data combined (e.g. Singer and Kivelson, 1979; Ruohoniemi et al., 1991; Walker et al., 1992; Takahashi et al., 1996; Laakso et al., 1998; Ohtani et al., 1999; Mann et al., 1998; 2002; Keiling et al., 2003).

FLRs are usually perceived as predominantly a dayside phenomenon with a preferential occurrence in the dawnside. However, HF radar, ground magnetometer and optical emission observations have also shown that ULF pulsations resulting from FLRs in the millihertz range (especially the $1-4 \mathrm{mHz}$ range) are a common feature of data in the nightside sector (e.g. Samson et al., 1991, 1992b and references therein). The link between FLRs and certain classes

Published by Copernicus GmbH on behalf of the European Geosciences Union. 


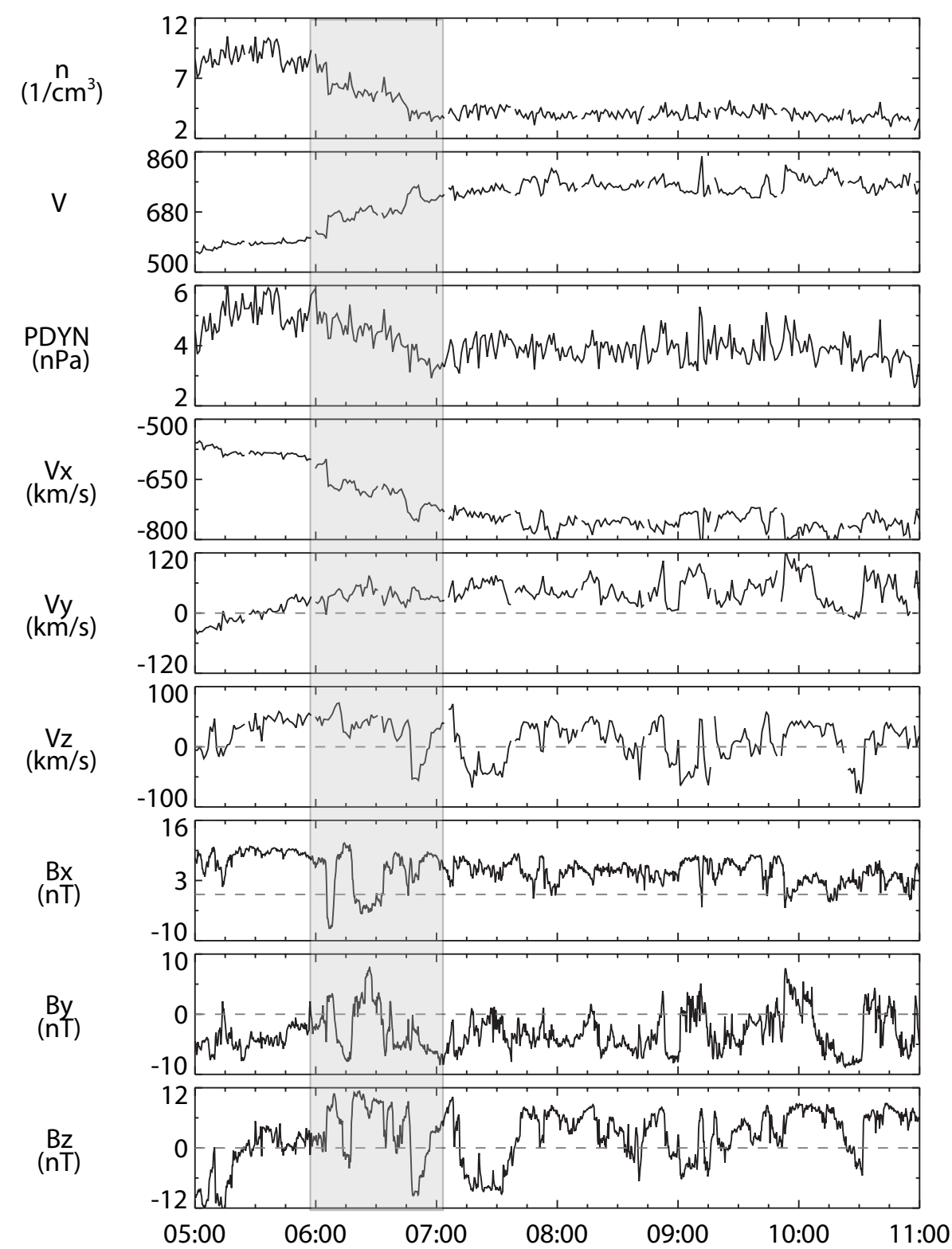

Fig. 1. Solar wind and IMF conditions measured by ACE spacecraft (it has been time-shifted by 38 min) during the interval 05:00-11:00 UT. From top to bottom are: density in $\mathrm{cm}^{-3}$, solar wind speed in $\mathrm{km} / \mathrm{s}$, solar wind dynamic pressure in $\mathrm{nPa}$, three components of solar wind velocity in $\mathrm{km} / \mathrm{s}$, and three components of the IMF in nT. The highlighted region in Fig. 1 indicates the interval during which the ULF pulsations were seen. GSM coordinates are used here.

of auroral arc formation has been reported and is gaining more support both observationally (e.g. Samson et al., 1992b; Lotko et al., 1998) and theoretically (e.g. Lui and Murphree, 1998; Streltsov and Lotko, 1999; Rankin et al. 1999).

FLRs can provide a self-consistent and comprehensive explanation of energy accumulation near magnetic surfaces where the frequency of global scale compressional waves matches the local field line eigenfrequency. FLRs can also account for density cavities in the low-altitude auroral acceleration region by nonlinear ponderomotive forces (Rankin et al., 1995) and the narrow structuring of auroral arcs through mode conversion to inertial Alfvén waves. They play an important role in understanding ULF pulsations in the magnetosphere and also serve as an important diagnostic tool in monitoring plasma mass density. For reviews on FLR research, see Takahashi (1998) and Glassmeier et al. (1999).

Among the numerous publications, few studies of FLRs have been reported using data in the magnetotail. In this paper we present, for the first time, convincing in situ evidence of FLRs of a very low frequency $(1.1 \mathrm{mHz})$ in the 


\section{Orbit/Configuration}

20030808 06:00 UT - 10:00 UT
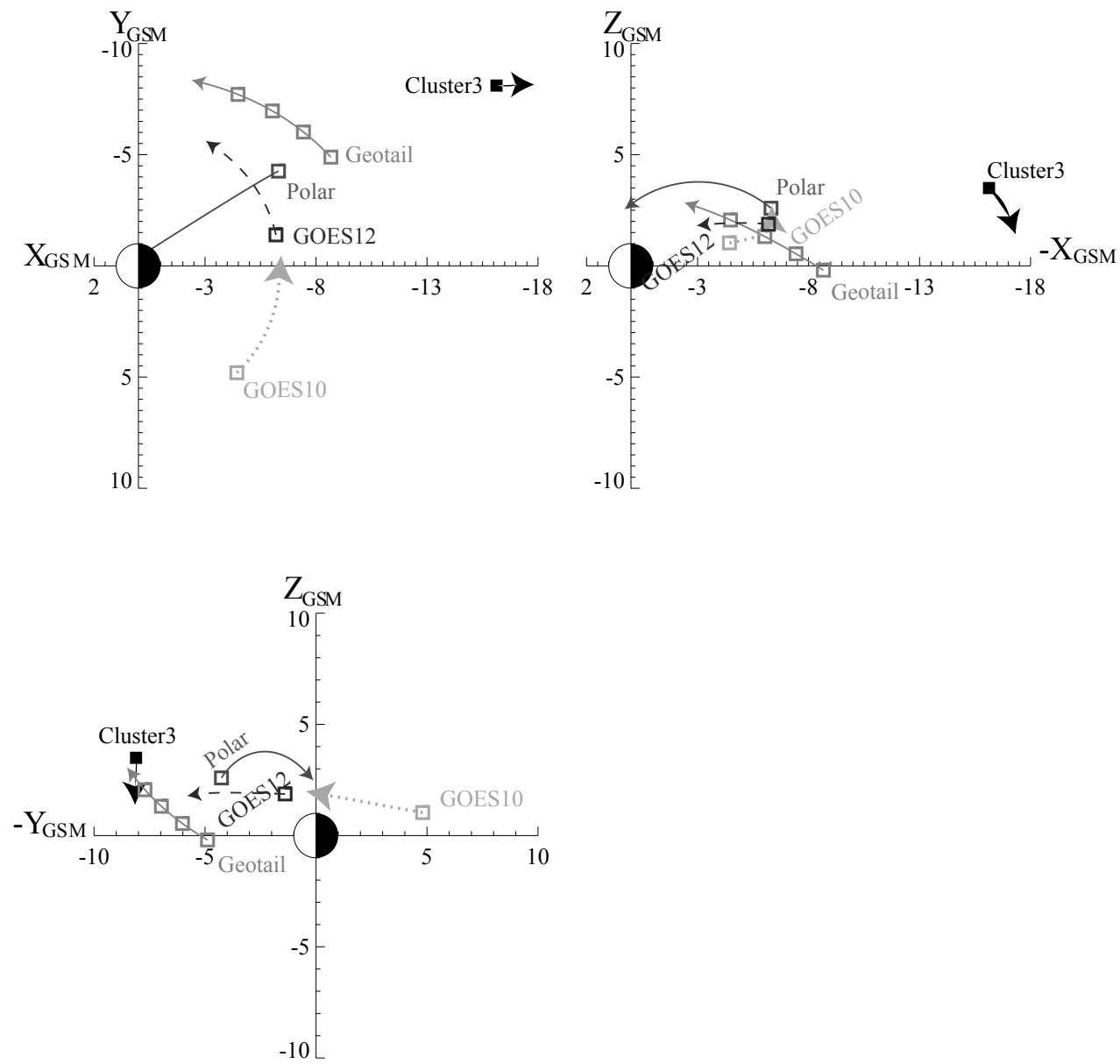

Fig. 2. The orbit configuration in three different planes ( $x-y, x-z$ and $y-z)$ in GSM during 06:00-10:00 UT for all the satellites involved in this study, with the arrows indicating the motion.

magnetotail at $l_{0} \approx 21 R_{E}$ (equatorial radial distance using Tsyganenko 96 model) observed by Cluster satellites. This event took place during the interval 06:00-07:00 UT on 8 August 2003. The expected latitudinal FLR amplitude and phase profile were also observed by ground magnetometer stations in the CANOPUS (now CARISMA) array near Cluster's footpoint, which provides further support to our interpretation of the event. The $1.1-\mathrm{mHz}$ pulsations were also observed by some of the ground stations of the Greenland Chains. Simultaneously, quasi-periodic oscillations at higher frequencies were registered by GOES 12, Polar and Geotail.

The organization of the paper is as follows: Sect. 2 provides the solar wind condition measured by ACE spacecraft. Detailed observations of ULF pulsations at different frequencies are given in Sect. 3, including data from several satellites and ground magnetometers. Discussion is provided in Sect. 4 and a summary is given in Sect. 5.

\section{Solar wind condition}

The magnetosphere was subject to a high-speed solar wind stream with an average speed of about $680 \mathrm{~km} / \mathrm{s}$, an average density of $4 \mathrm{~cm}^{-3}$ and dynamic pressure of $4 \mathrm{nPa}$ during the event. The IMF (interplanetary magnetic field) $B_{z}$ had an average value of $3.8 \mathrm{nT}$. Both the IMF and solar wind velocity were oscillatory. Figure 1 shows the detailed measurements from the ACE spacecraft (it has been time-shifted by 38 min to the Cluster location in the mid-tail) during the interval 05:00-11:00 UT. From top to bottom are: density in $\mathrm{cm}^{-3}$, solar wind speed in $\mathrm{km} / \mathrm{s}$, solar wind dynamic pressure in $\mathrm{nPa}$, three components of solar wind velocity in $\mathrm{km} / \mathrm{s}$, and three components of the IMF in $\mathrm{nT}$. The highlighted region in Fig. 1 indicates the interval during which the ULF pulsations were seen. The Geocentric Solar Magnetospheric (GSM) coordinate system is used here. 


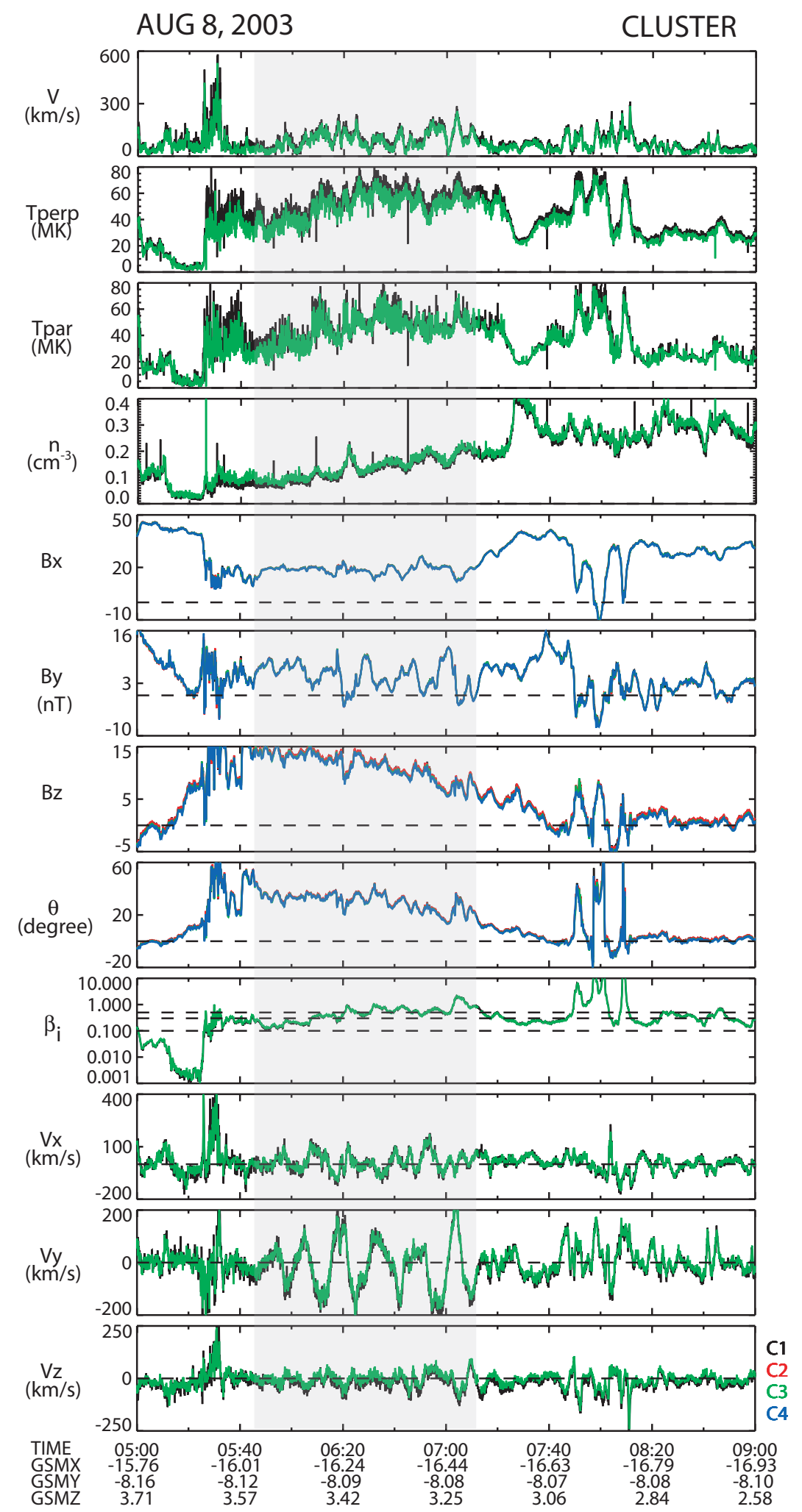

Fig. 3. Cluster data during 05:00-0900 UT, including both ion moment data and magnetic field data. The highlighted region is the interval during which quasi-periodic oscillations were seen. Figure 3 serves as an observational context for the oscillations. 
(a)

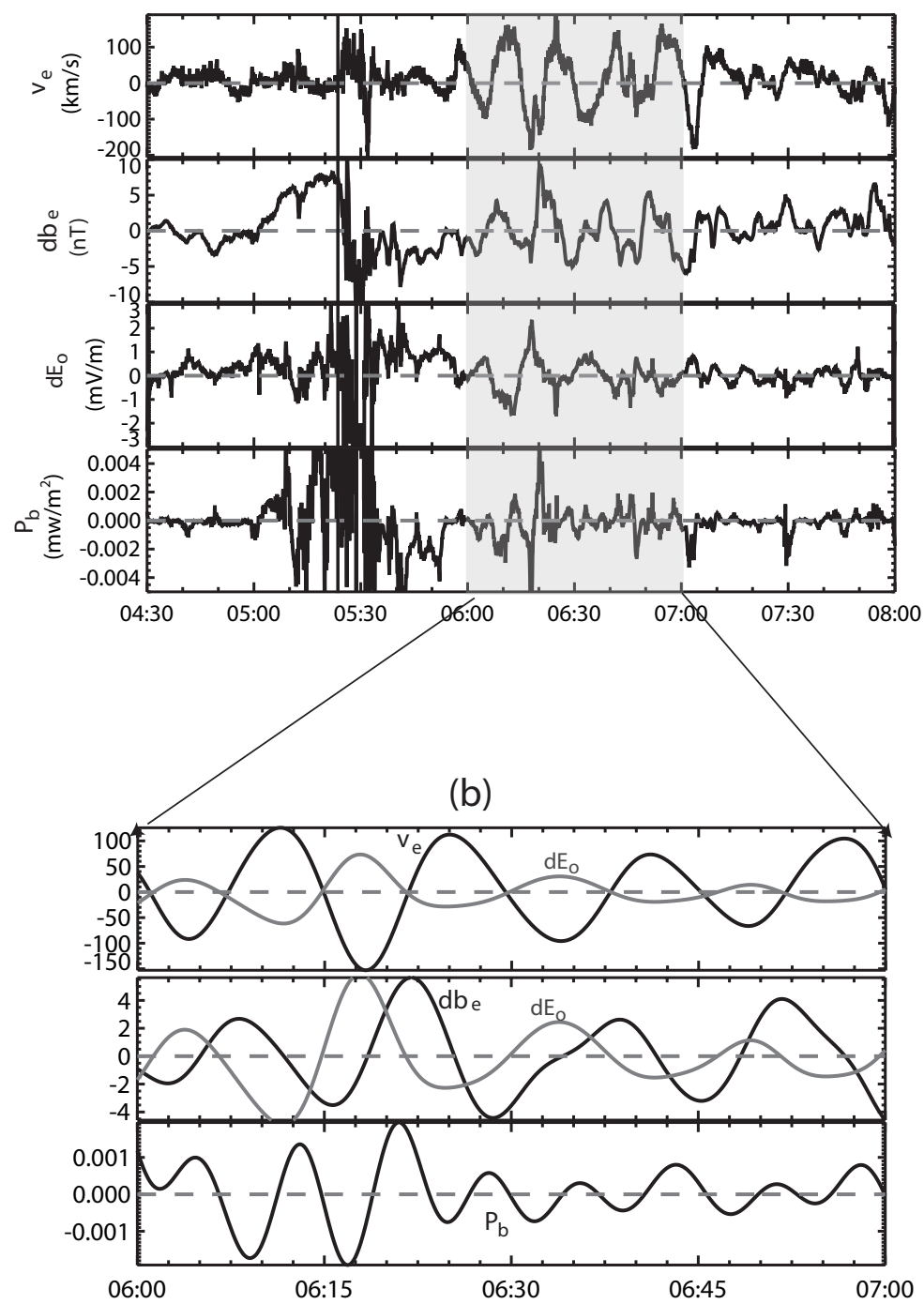

Fig. 4. Parameters of oscillations seen on 8 August 2003 by Cluster 3 in magnetic field-aligned coordinates (see text for details) with (a) showing the unfiltered data and (b) showing an expanded view of the event with a band-pass filter [0.4 $\mathrm{mHz}, 2.5 \mathrm{mHz}] \mathrm{applied}$.

\section{Observations}

\subsection{Orbit configuration}

Figure 2 shows the orbit configuration in three different planes (x-y, x-z and $y-z$ ) in GSM during 06:00-10:00 UT for all the satellites involved in this study, with the arrows indicating the moving direction. We can see that Cluster was located further down in the tail, while GOES 10, GOES 12, Polar and Geotail were closer to the Earth. It is worth noting that only GOES 10 was located in the pre-midnight, while all the other satellites were in the post-midnight.

\subsection{Oscillations at $1.1 \mathrm{mHz}$}

The 1.1-mHz quasi-periodic oscillations were observed by Cluster in the mid-tail and some of the ground magnetometer stations in the CANOPUS and Greenland chains around Cluster's footpoint.

\subsubsection{Cluster in-situ measurements}

Cluster was located in the plasma sheet near 02:00 magnetic local time (MLT). Due to the small separation $(<300 \mathrm{~km})$ between the four Cluster spacecraft, the measurements from the four spacecraft are almost identical. Here we use Cluster 3 (C3) as the reference spacecraft. Figure 3 shows Cluster data during 05:00-0900 UT, including both ion moment data 


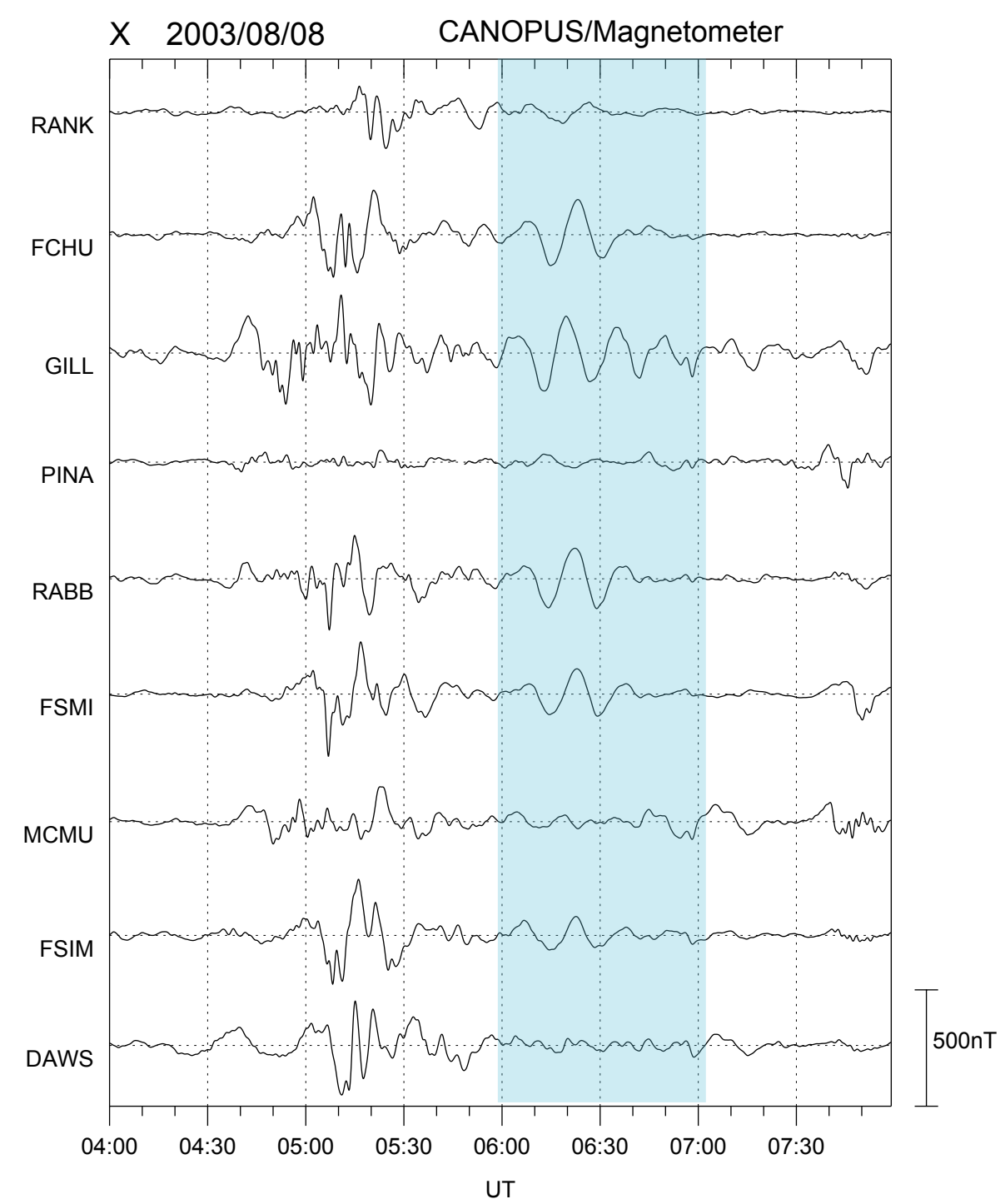

Fig. 5. The band-pass (with cut-off periods of 100-2000 s) filtered data in the $X$ (geographic north) component from the CANOPUS chains (Here $\mathrm{X}$ is very close to $\mathrm{H}$, local magnetic north, as the angle between them is only about $3^{\circ}$ ). Very monochromatic $1.1-\mathrm{mHz}$ oscillations with large amplitudes were detected by several CANOPUS stations.

from the HIA (hot ion analyzer) component of the CIS (Cluster Ion Spectrometry) (Rème et al., 2001) instrument and magnetic field data from the FGM (FluxGate Magnetometer) measurements (Balogh et al., 2001). The highlighted region is the interval during which quasi-periodic oscillations were seen. Figure 3 serves as an observational context for the oscillations. Cluster traversed several different plasma regions during the four-hour interval mainly because of the dynamical changes in the magnetotail: the lobe region (05:14-05:24 UT, due to plasma sheet thinning), plasma sheet boundary layer $(05: 24-05: 45$ UT), plasma sheet region (05:45-08:00 UT), the region of neutral sheet crossing ( 07:50-08:20 UT). A dipolarization event took place around 05:25 UT accompanied by relatively large flows.
Quasi-periodic oscillations were most noticeable in $V_{y}$ and $B_{y}$ with a period of $15 \mathrm{~min}$ and frequency at $1.1 \mathrm{mHz}$ during 06:00-07:15 UT. C3 started from $(-16.13,-8.11,3.50) R_{E}$ in GSM coordinates at 06:00 UT, going towards the equator. During the 1-h interval, Cluster's position did not change much, with $\mathrm{C} 3$ at $(-16.44,-8.08,3.25) R_{E}$ at 07:00 UT. The average plasma ion beta during the one-hour interval was about 0.5 , ion density was $0.1-0.2 \mathrm{~cm}^{-3}$, the average ion temperature was about $5 \mathrm{keV}$ and the average angle between the magnetic field direction and the equatorial plane is $\sim 30^{\circ}$.

Figure 4 shows the oscillating physical quantities in fieldaligned coordinates, with (a) containing unfiltered measurements at 4-s resolution and (b) presenting expanded views of the event with a band-pass filter between $400 \mathrm{~s}$ and $2400 \mathrm{~s}$ 


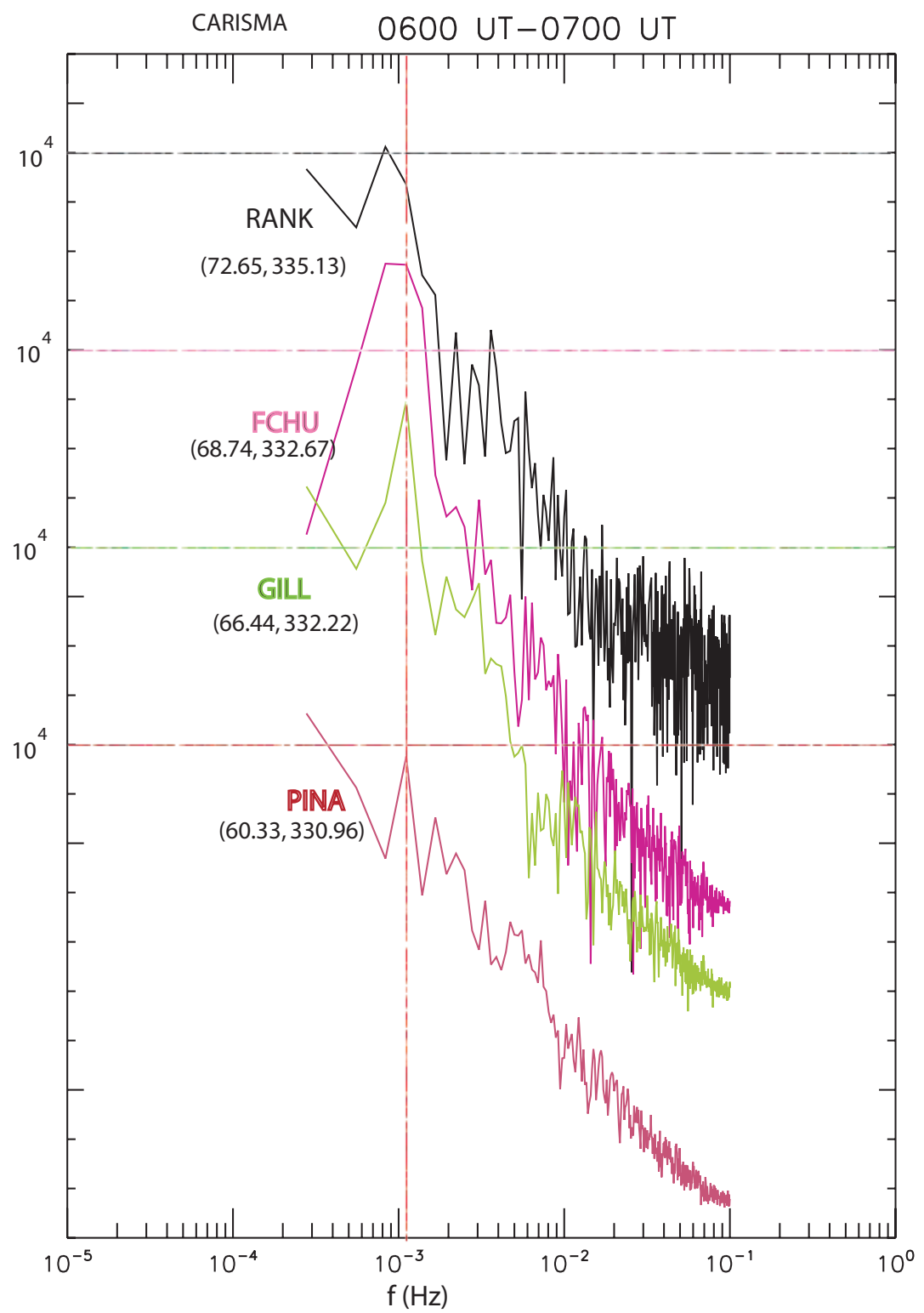

Fig. 6. The power spectra along the north-south Churchill line using the data within the one-hour interval 06:00-0700 UT.

$(0.4-2.5 \mathrm{mHz})$. In the field-aligned coordinates, "o" is in $-\boldsymbol{B}_{0} \times\left(\boldsymbol{B}_{0} \times \boldsymbol{r}\right)$ direction - napproximately radially outward, "e" is in the direction of $\left(\boldsymbol{B}_{0} \times \boldsymbol{r}\right)$ - approximately eastward and ' $b$ ' is in the direction of the magnetic field $\boldsymbol{B}_{0}$, where $\boldsymbol{B}_{0}$ is the 1-h running average of the measured magnetic field and $\boldsymbol{r}$ represents the spacecraft's location.

The top panel of Fig. 4a shows the azimuthal ion velocity $V_{e}$ in $\mathrm{km} / \mathrm{s}$ with its varying amplitude up to $150 \mathrm{~km} / \mathrm{s}$, the second panel is the perturbed azimuthal magnetic field $d b_{e}$ in nT with its amplitude up to $10 \mathrm{nT}$, the third panel shows the perturbed radial electric field $d E_{o}$ in $\mathrm{mV} / \mathrm{m}$ (an amplitude of $3 \mathrm{mV} / \mathrm{m}$ ) and the bottom panel is the magnetic field-aligned Poynting vector $P_{b}$ (from the two components $d E_{o}$ and $d b_{e}$, the contribution from $-\boldsymbol{d} \boldsymbol{E}_{\boldsymbol{e}} \times \boldsymbol{d} \boldsymbol{b}_{\mathbf{0}}$ being negligible). The electric field data are obtained from the EFW (Electric Fields and Waves) (Gustafsson et al., 1997) instrument. Since the EFW instrument only has two axes, $\boldsymbol{E} \cdot \boldsymbol{B}=0$ is assumed in obtaining the electric field. The field-aligned Poynting vector oscillates at about twice of the FLR frequency with its amplitude up to $4 \mu \mathrm{W} / \mathrm{m}^{2}$. The shaded region is to show the interval when FLR oscillations were seen.

The top panel of Fig. 4b shows filtered $V_{e}$ (in black) and $d E_{o}$ (in grey) with $\mathrm{dE}_{0}$ being multiplied by a factor of 50. The second panel is the overlapping plot of $d b_{e}$ (black) and $d E_{o}$ (grey), where $\mathrm{dE}_{0}$ was multiplied by 4 . The last panel shows the field-aligned Poynting vector resulted from the 


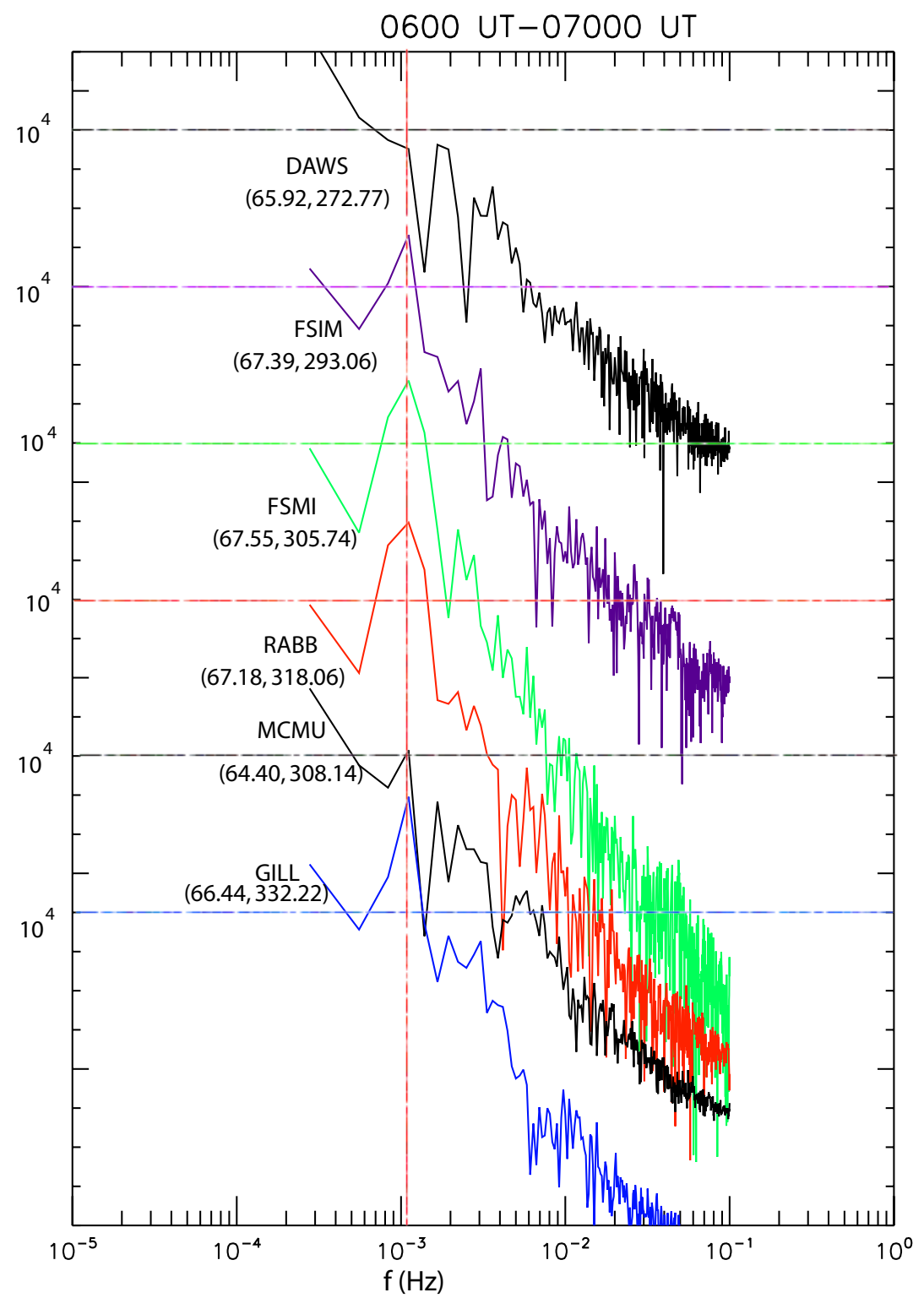

Fig. 7. The power spectra for all the stations along the west-east direction with the same format as Fig. 6 .

filtered fields in the top two panels. That $V_{e}$ and $d E_{0}$ are $180^{\circ}$ out of phase is to be expected. The fact that $d b_{e}$ and $d E_{o}$ are $90^{\circ}$ out of phase and the field-aligned Poynting flux oscillates at twice of the FLR frequency confirms that these oscillations are standing Alfvén waves (Fenrich et al., 1995). The oscillations belong to the toroidal mode as the oscillations are mainly in $V_{e}, d b_{e}$ and $d E_{o}$. The cross phase between $d b_{e}$ and $V_{e}$ is $90^{\circ}$, indicating the observed wave is a fundamental mode and the spacecraft was located above (North to) the equatorial node of B. Therefore quasi-periodic oscillations at $1.1 \mathrm{mHz}$ observed by Cluster are proven to be toroidal standing Alfvén waves.

\subsubsection{The $1.1 \mathrm{mHz}$ ground-based observations}

The 1.1-mHz oscillations were also seen on the ground across most of the CANOPUS and Greenland magnetometer arrays.

Figure 5 shows the band-pass filtered (with cut-off periods: 100-2000 s) data in the X (geographic north) component from the CANOPUS chains (Here $\mathrm{X}$ is very close to $\mathrm{H}$, local magnetic north, as the angle between them is only about $3^{\circ}$ ). Very monochromatic $1.1-\mathrm{mHz}$ oscillations (were also seen in the raw data) with large amplitudes were detected by several CANOPUS stations, such as Gillam (GILLL), Fort Churchill (FCHU), Rabbit Lake (RABB), Fort Smith (FSMI) and Fort Simpson (FSIM), with GILL having the 


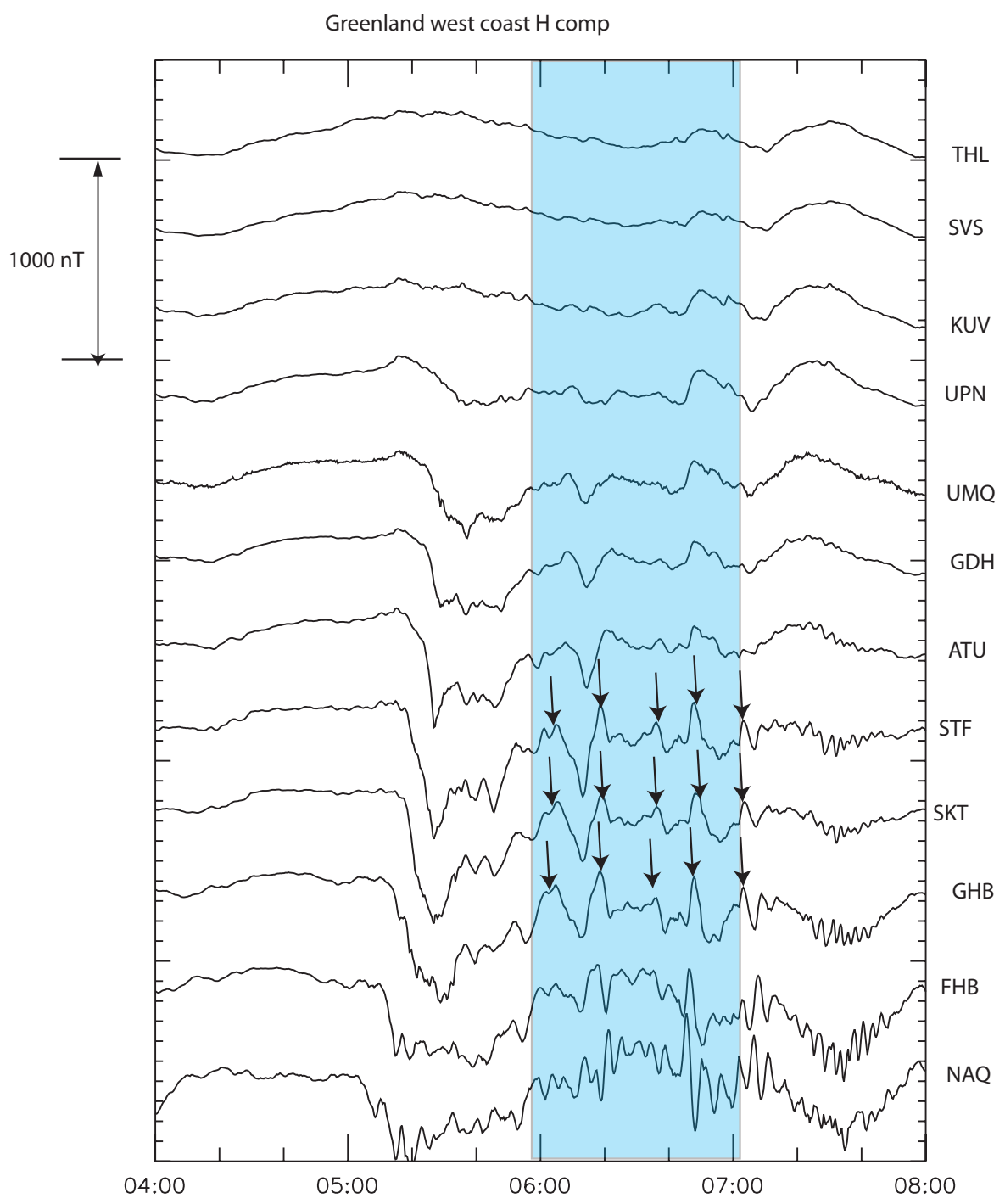

Fig. 8. The stacked H component data from the Greenland west coast magnetometers. It is in the order of decreasing latitude from top to bottom.

largest amplitude (peak to peak amplitude of $\sim 400 \mathrm{nT}$ ) and longest duration. These oscillations occurred right after a substorm. Figure 6 shows the power spectra resulting from the FFT (Fast Fourier Transform) analysis along the northsouth Churchill line. All power spectra plots here use the data within the one-hour interval 06:00-07:00 UT. The CGM (corrected geomagnetic) longitude and latitude pair is indicated for each station. The reference power of $10^{4} \mathrm{nT}^{2} \mathrm{~Hz}$ is also shown for easy comparison. Figure 7 is the power spectra for all the stations along the west-east direction with the same format as Fig. 6. 1.1-mHz peaks are obvious in Figs. 6 and 7.

The stacked $\mathrm{H}$ component data from the Greenland west coast magnetometers is shown in Fig. 8 in the order of decreasing latitude. Figure 9a shows the power spectra for the northern stations while Fig. $9 \mathrm{~b}$ shows those of the southern stations in Greenland's west coast, in the order of increasing latitude. The power spectra for the Greenland east coast stations are shown in Fig. 10. Besides the $1.1-\mathrm{mHz}$ spectra peak, there are also other spectra peaks: such as the $1.6 \mathrm{mHz}$ and $\sim 3.0 \mathrm{mHz}$ ones in the Greenland west coast stations and the $\sim 2.1 \mathrm{mHz}$ in Greenland's east coast. The latitude independent $1.1-\mathrm{mHz}$ spectra peak at almost all of the CANOPUS and Greenland stations is apparent, indicating a driven field line resonance at this discrete frequency. The 1.1-mHz pulsations at Kangerlussuaq (STF), Maniitsoq (SKT) and Nuuk (GHB) in Greenland's west coast are less coherent, compared to those at CANOPUS stations. Notice that the pulsations took place after a substorm at CANOPUS locations while the pulsations were still inside the substorm at Greenland. The substorm may have had some effects on the coherence of the waves. 


\section{Greenland westcoast northern stations}

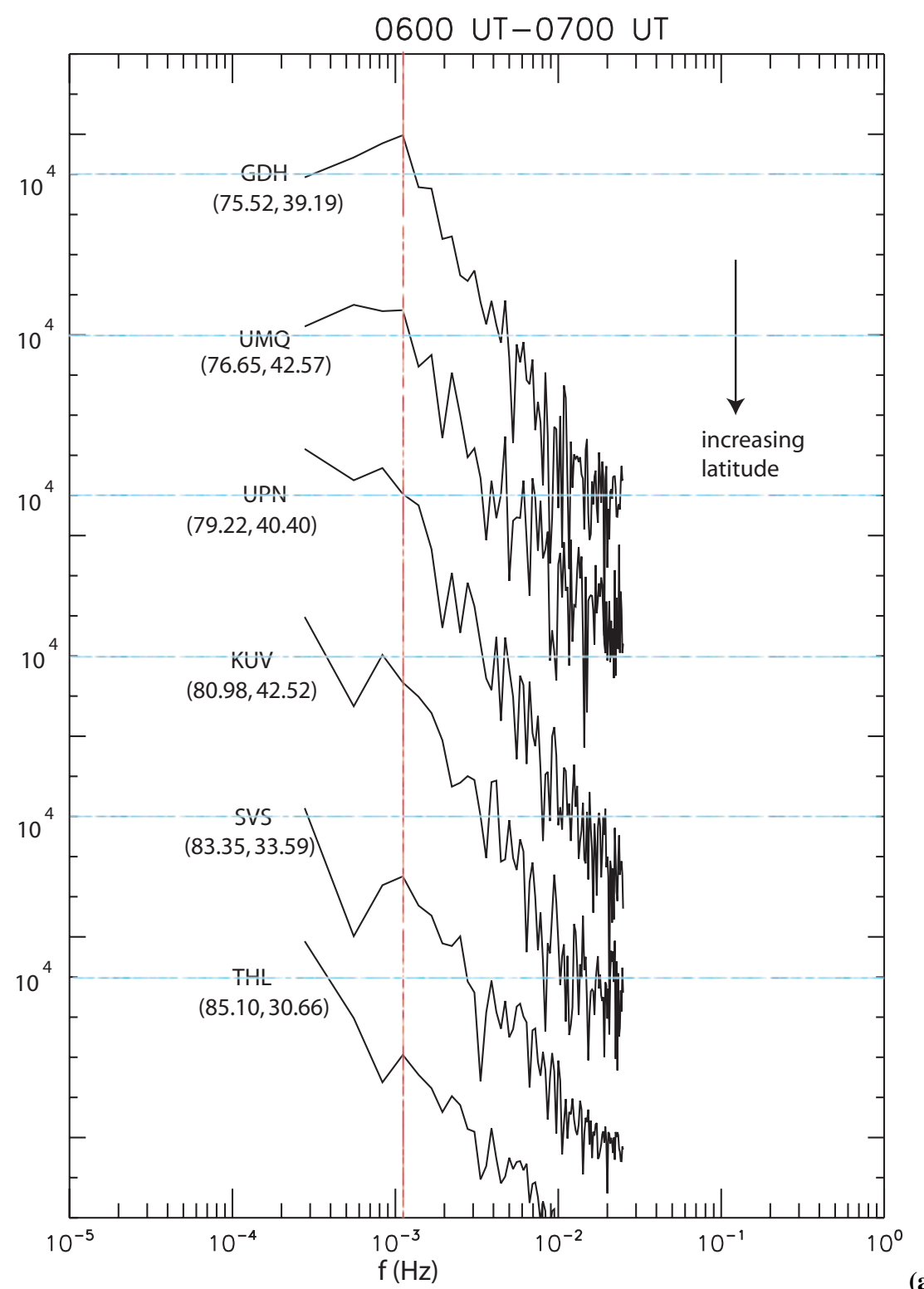

(a)

Fig. 9. (a) The power spectra for the northern stations and (b) the power spectra for the southern stations in Greenland's west coast in the order of increasing latitude;

The $\mathrm{H}$ component data from both the CANOPUS and Greenland chains shows the clear poleward phase propagation which is expected for a driven FLR (e.g. Wright and Allan, 1996). The complex demodulation analysis (e.g. Mathie and Mann, 2000) of the $1.1-\mathrm{mHz}$ wave from the Churchill line, shown in Fig. 11, further confirms that. Figure 11a shows the amplitude versus CGM latitude for both the $\mathrm{H}$ and D component and Fig. 11b shows the phase versus CGM latitude for the two components. The complex demodulation is a time series analysis technique which allows an estimation of the temporal variation of the amplitude and phase of particular frequency components of a time series. The FLR characteristic is verified by the amplitude maximum between GILL and FCHU and $180^{\circ}$ latitudinal (CGM latitude is used here) phase change in the H-component. The dominance of $\mathrm{H}$ component on the ground is expected for a dominantly toroidal wave in space observed by Cluster due to ionospheric rotational effects.

Figure 12 shows the $1.1-\mathrm{mHz}$ ground observations in longitudinal order, from stations in the premidnight sector (CANOPUS: top panel) to those in the post-midnight/early morning sector (Greenland: bottom panel). The 1.1-mHz 


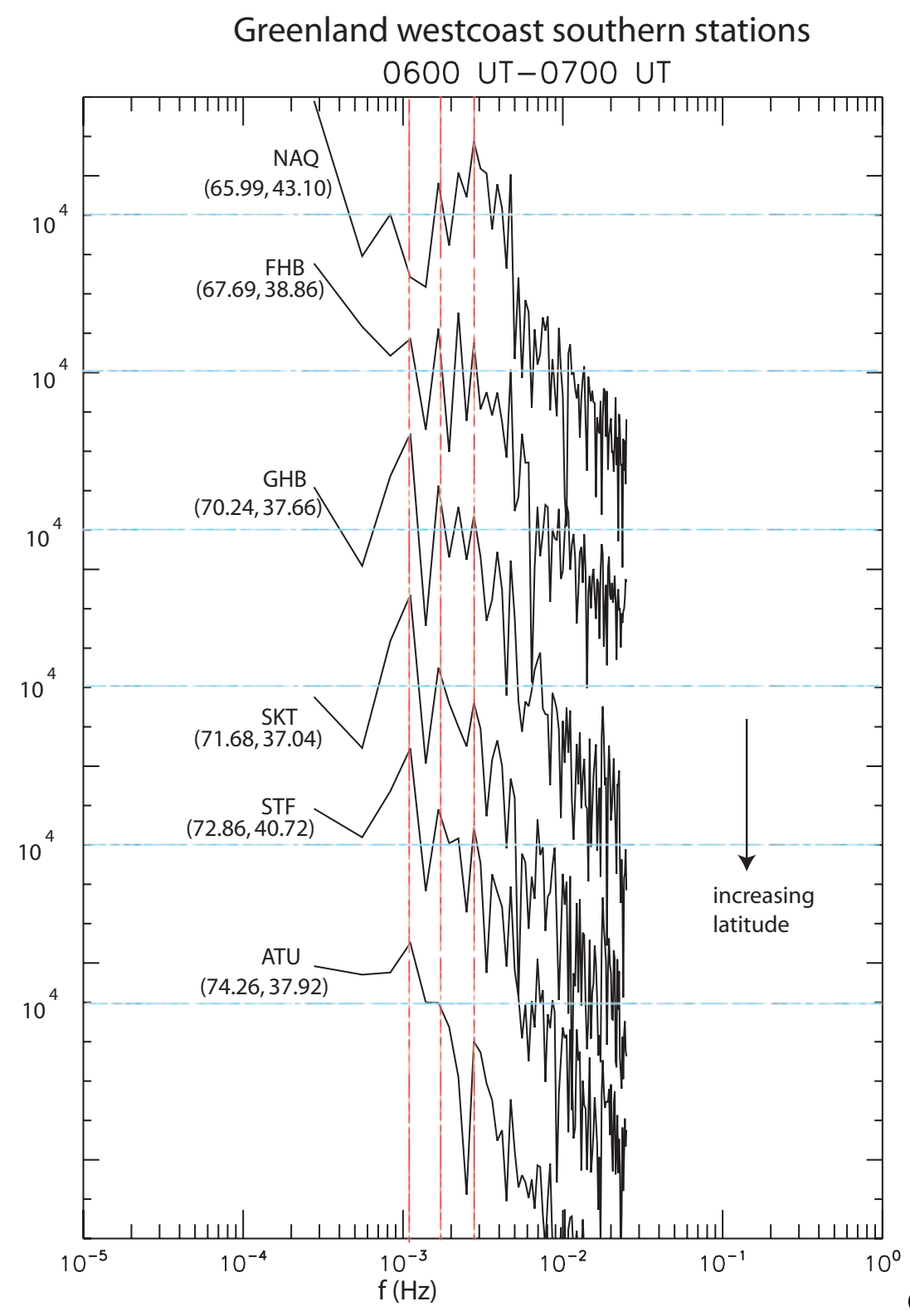

(b)

Fig. 9. Continued.

wave spanned over a very large longitudinal range and had a westward propagation as the easternmost station Daneborg (DNB) saw it first. The excited FLR seemed to get damped while going westward as stations in the east (post-midnight) saw more waveforms than those in the west (pre-midnight). By comparing the instantaneous values of the D component phase between the longitudinally spaced CANOPUS station pair (FSMI-GILL) of 1.1-mHz FLR, an estimation of the azimuthal wave number m (e.g. Mann et al., 2002) was obtained, with $\mathrm{m}=-1.2 \pm 0.1$ (the $\mathrm{H}$-component gives $\mathrm{m}=-1.6 \pm 0.1)$. The $\mathrm{D}$ component is chosen as the more reliable indicator of the azimuthal propagation as it is not as susceptible as the $\mathrm{H}$ component to large phase changes in the vicinity of a resonance. The negative value of $\mathrm{m}$ is consistent with the westward propagation in Fig. 12 and the low $\mathrm{m}$ value is expected for the efficient coupling of compressional energy to shear Alfvén FLRs. The negative $m$ value is also consistent with the tailward and westward propagation of the wave front by utilizing the four Cluster spacecraft. Using the relationship $V_{\mathrm{ph}}=2 \pi \mathrm{R}_{\mathrm{E}} \cos \lambda / \mathrm{m}$, we found ionospheric azimuthal phase speed $\left(V_{p h}=12.8 \mathrm{~km} / \mathrm{s}\right)$ for the $1.1-\mathrm{mHz}$ FLR, which is in the range of $9 \leq \mathrm{V}_{\mathrm{p}} \mathrm{h} \leq 17 \mathrm{~km} / \mathrm{s}$ reported by Ziesolleck and McDiarmid (1994).

The summary of $1.1-\mathrm{mHz}$ wave observations is shown in Fig. 13 in terms of the MLT (magnetic local time)-Mlat (magnetic latitude) map. Strong magnetic pulsations with 


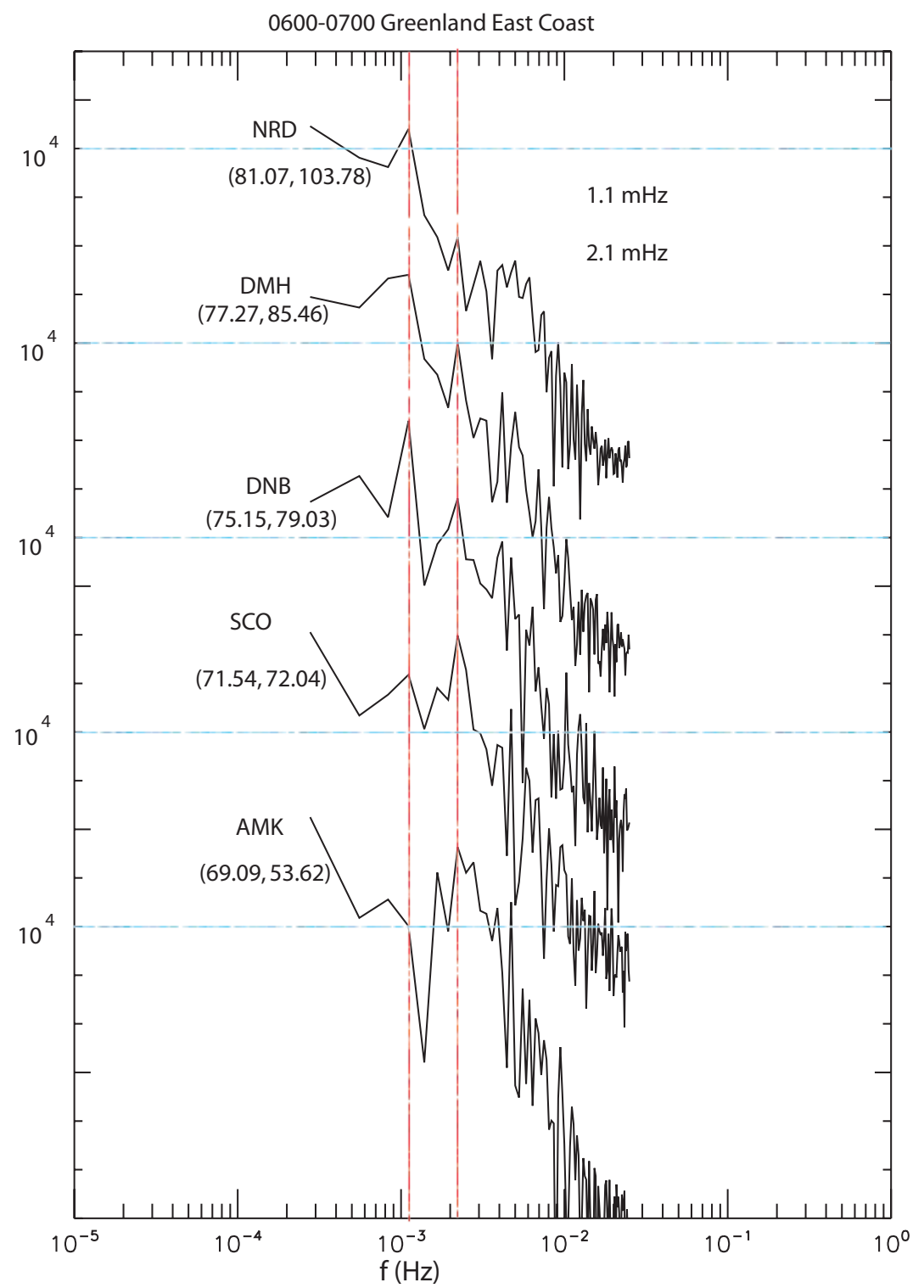

Fig. 10. The power spectra for stations in Greenland's east coast.
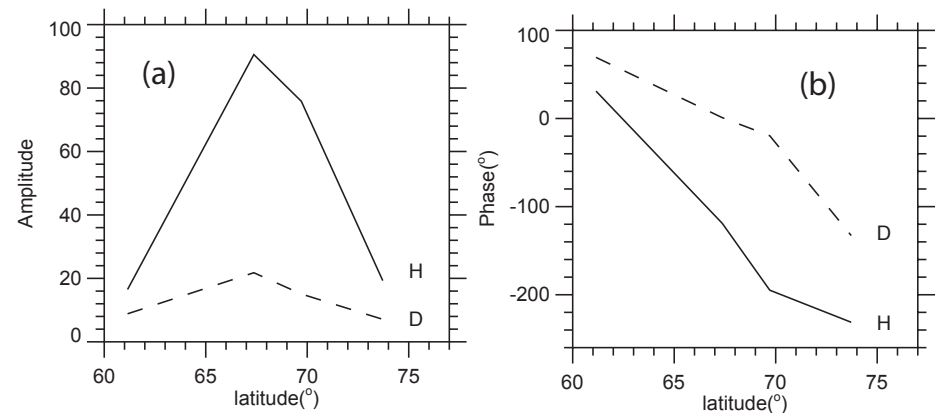

Fig. 11. The complex demodulation analysis of the $1.1-\mathrm{mHz}$ wave from the CANOPUS Churchill line. The FLR characteristic is verified by the amplitude maximum between GILL and FCHU and the $180^{\circ}$ latitudinal (CGM latitude is used here) phase change in the $\mathrm{H}$-component. 


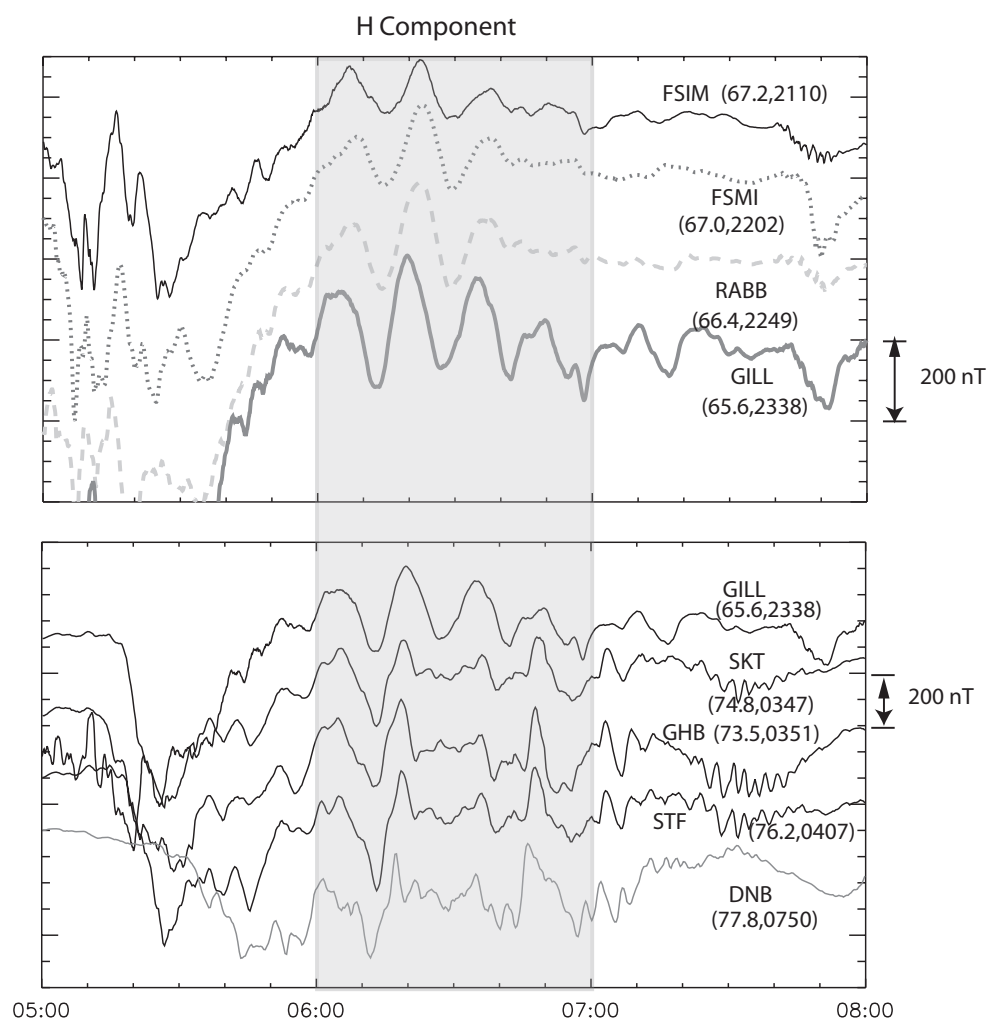

Fig. 12. Part of the ground-based 1.1-mHz pulsations in longitudinal order. Notice the westward propagation of the 1.1-mHz waves.

spectral amplitude greater than $10^{6} \mathrm{nT}^{2} / \mathrm{Hz}$ were found at GILL and RABB of the CANOPUS chain, SKT, GHB and STF in Greenland's west coast, and DNB in Greenland's east coast, which are indicated by a black "+". Stations with less wave power are indicated by a green "+". The map shows that the occurrence of the $1.1-\mathrm{mHz}$ pulsation moved to higher latitude with location further into the post-midnight local time. The Tsyganenko magnetic field model T96 (Tsyganenko, 1995) with solar wind dynamics pressure of $4.3 \mathrm{nPa}$, Dst of $-53 \mathrm{nT}$, IMF $B y$ of $-2.1 \mathrm{nT}$ and $B_{z}$ of $3.8 \mathrm{nT}$ puts Cluster's footpoint $\left(70.3^{\circ}, 01: 53,21.2 R_{E}-\right.$ this triplet represents MLAT-MLT- equatorial crossing distance $l_{0}$ ) in between GILL $\left(66.4^{\circ}, 23: 38,21.9 R_{E}\right)$ and GHB $\left(70.2^{\circ}, 03: 51\right.$, $\left.16.8 R_{E}\right)$. The parameters for other stations are: RABB $\left(67.1^{\circ}, 22: 49,18.9 R_{E}\right)$, SKT $\left(71.7^{\circ}, 03: 47,20.1 R_{E}\right), \mathrm{STF}$ $\left(72.9^{\circ}, 04: 07,22.2 R_{E}\right)$, and DNB $\left(75.2^{\circ}, 07: 00,18.5 R_{E}\right)$. We can see that the large amplitude $1.1-\mathrm{mHz}$ wave occurred on similar field lines with the average $l_{0}$ about $20 R_{E}$.

No one would likely doubt that Cluster could be located on a field line with an equatorial crossing distance $l_{0}$ of $21.9 R_{E}$ as its location $\left(\sim 19 R_{E}\right.$ in radial distance and the off-equator position) in the mid-tail suggested so. However, it is hard to believe intuitively that Gillam could be on a similar stretched field line. There are always controversies over magnetic field line mapping using empirical models such as Tsyganenko models. However, the observational evidence

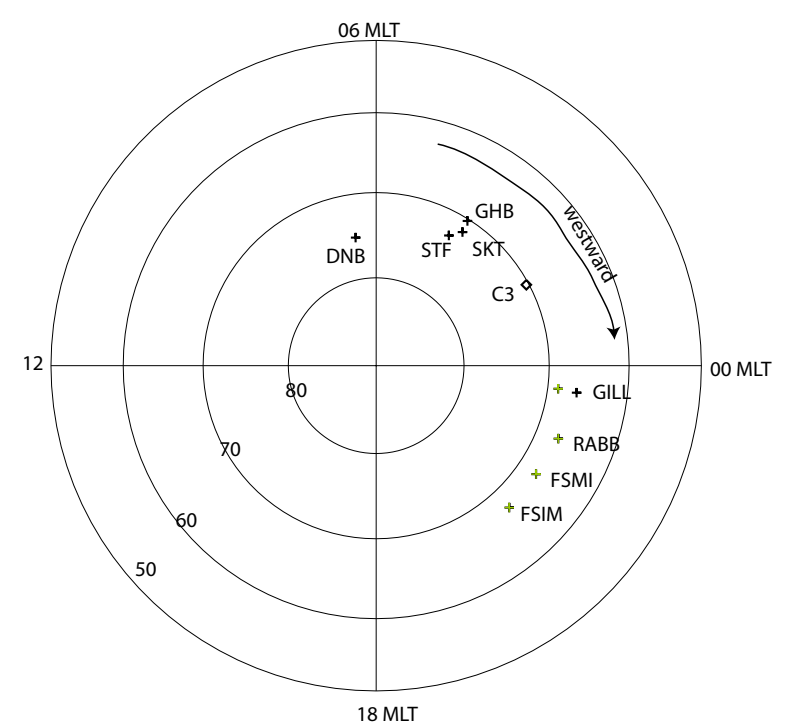

Fig. 13. The summary of $1.1-\mathrm{mHz}$ wave observations in terms of the MLT-Mlat map.

of a driven field line resonance at the discrete frequency of $1.1 \mathrm{mHz}$ with the resonance near Gillam from CANOPUS data, together with the simultaneous observation of the same frequency standing toroidal Alfvén wave by Cluster in space 


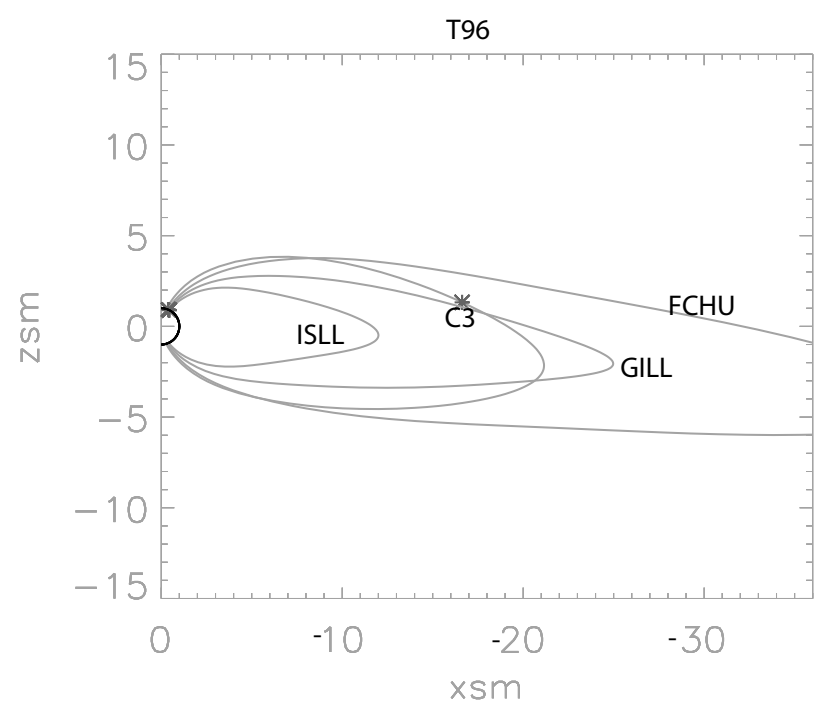

T05 (with Ws)

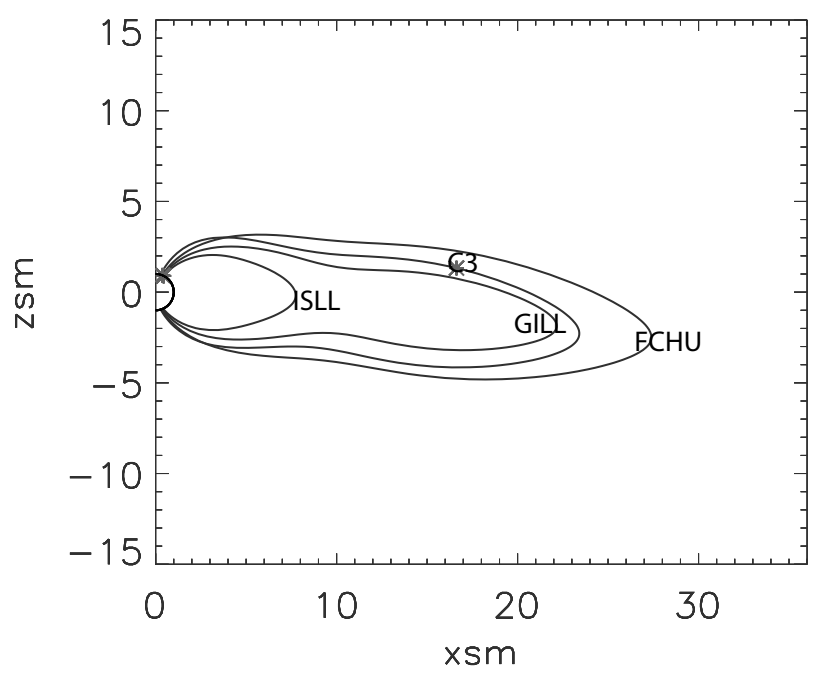

$$
\begin{aligned}
& \operatorname{parmod}(1)=\text { Pdyn }=4.3 \\
& \operatorname{parmod}(2)=\text { Dst }=-53 \\
& \operatorname{parmod}(3)=I M F B y=-2.1 \\
& \operatorname{parmod}(4)=I M F B z=3.8 \\
& \operatorname{parmod}(5)=\mathrm{W} 1=0.7 \\
& \operatorname{parmod}(6)=\mathrm{W} 2=0.5 \\
& \operatorname{parmod}(7)=\mathrm{W} 3=0.3 \\
& \operatorname{parmod}(8)=\mathrm{W} 4=1.0 \\
& \operatorname{parmod}(9)=\mathrm{W} 5=0.68 \\
& \operatorname{parmod}(10)=\mathrm{W} 6=1.60
\end{aligned}
$$

Fig. 14. Modeled magnetic field lines in the $x-y$ plane in SM coordinates with (a) from the T96 model and (b) from the T05 model. The magnetotail is rather stretched from both models. argue strongly that Cluster and Gillam could be on similar field lines. Here we use Tsyganenko models as a reference in interpreting the data. With the same set of solar wind, IMF and Dst parameters as mentioned above, Tsyganenko 2005 model - T05 (Tsyganenko and Sitnov, 2005) also gives the equatorial crossing distances similar to those of T96 even though the $l_{0}$ values are relatively smaller (see bottom panel of Fig. 14). $l_{0}$ at Gillam is still around $20 R_{E}$ using T05. The history of solar wind and IMF conditions and the different response time of magnetospheric current systems are taken into account in T05. The corresponding $\mathrm{W}$ parameters $(W 1=0.7, W 2=0.5, W 3=0.3, W 4=1.0, W 5=0.68, W 6=1.6)$ based on ACE data for the event are also shown in Fig. 14. Figure 14 shows the field line tracing results projected in the $\mathrm{X}-\mathrm{Z}$ plane (in SM coordinates) with top panel from the T96 model and bottom panel from the T05 model. Remember that Gillam and Cluster 3 were in different meridianal plane (different local time) and their field lines using T96 don't cross in the 3 -D picture. Even though the average IMF $B_{z}$ was positive, the large solar wind dynamic pressure $(4.3 \mathrm{nPa})$ and a Dst value of $-53 \mathrm{nT}$ (rendering relatively strong ring current) are both likely to create a stretched magneotail.

\subsection{Pulsations at other higher frequencies}

Closer to Earth compared to Cluster, Polar $\left(66.1^{\circ}-66.8^{\circ}\right.$, 01:46, $\left.11-14 R_{E}\right)$, Geotail $\left(65.9^{\circ}, 02: 00,9.8 R_{E}\right)$ and GOES $12\left(63.3^{\circ}, 00: 55,8.7 R_{E}\right)$ also observed quasiperiodic oscillations during the event, noticeable in $\mathrm{db}_{\mathrm{e}}$ for Polar, in $V_{x}$ and $V_{y}$ (GSM) for Geotail and in $B_{y}$ (GSM) for GOES 12 (see Fig. 15). Therefore azimuthal oscillations are an obvious feature in all three satellites. The fact that oscillations were found in $V_{y}$ but not in $B_{y}$ by Geotail indicates the observed wave had a node of $\mathbf{B}$ at the equator as Geotail was very close to the equatorial region. The observed different discrete frequencies are $1.4 \mathrm{mHz}$ (Polar: after 06:25 UT), $1.9 \mathrm{mHz}$ (Polar: prior to $06: 25 \mathrm{UT}$ ) and $2.5 \mathrm{mHz}$ (Geotail and GOES 12). However, there were no clear oscillations seen by GOES10, which was located in the pre-midnight.

The quasi-periodic oscillations observed at the multiple spacecraft in space and on the ground are believed to be manifestations of the field-line resonances, as the peak frequency is found to have L-shell dependence that is in agreement with the FLR theory (Fig. 16).

\section{Discussion}

The apparent westward propagation displayed in Fig. 12 and the negative $\mathrm{m}$ value in the near midnight/early morning sector indicate that the $1.1-\mathrm{mHz}$ FLR was possibly driven by a wave source at the discrete frequency $(1.1 \mathrm{mHz}) \mathrm{re}-$ sulted from the flank MHD cavity/waveguide (Samson et al., 1992a) mode, propagating tailward. Research results have shown that the compressional waveguide/cavity modes 
(a)

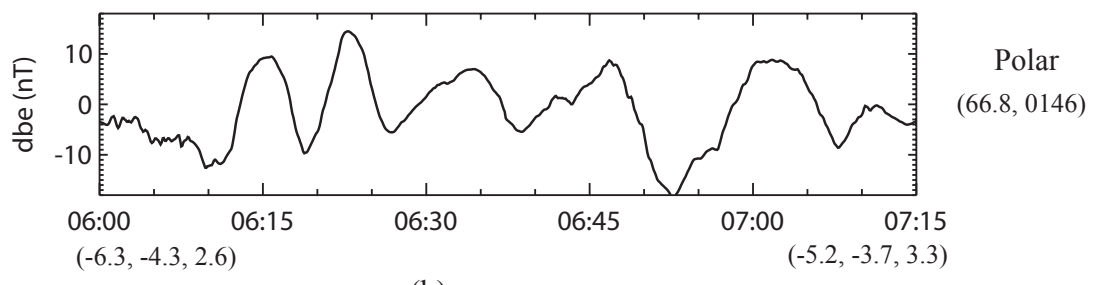

(b)
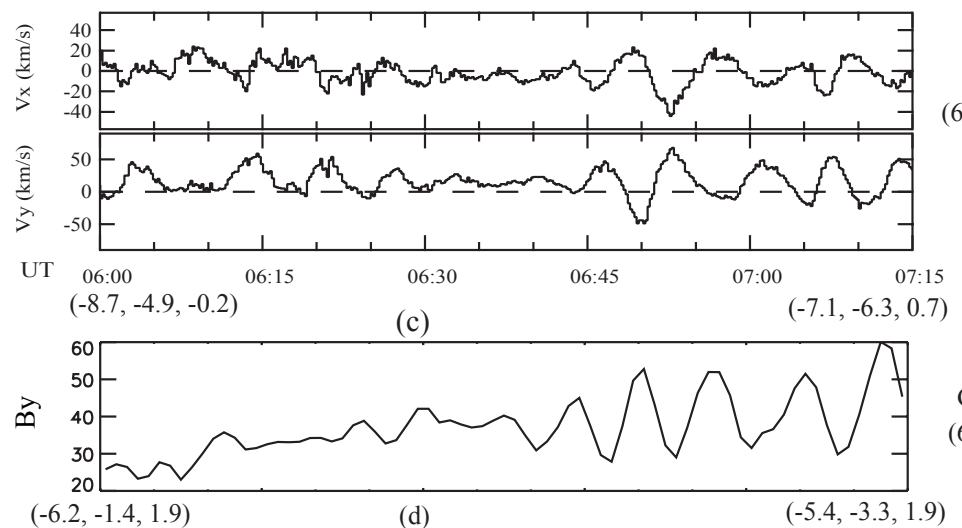

GOES 12

$(63.3,0055)$

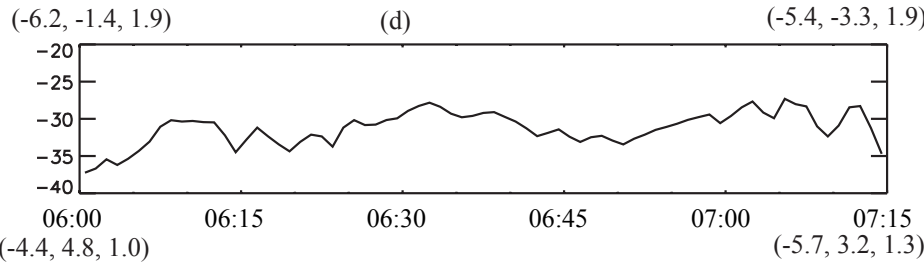

GOES 10

$(62.3,2118)$

Fig. 15. Oscillations at different frequencies observed by Polar in (a), Geotail in (b), GOES 12 in (c), and GOES 10 in (d).

can be excited by a variety of sources including solar wind and IMF variability, transient dayside reconnection, Kelvin Helmholtz instabilities (KHIs) in the low-latitude boundary layer (LLBL) and substorm associated instabilities. In this case, substorm related instabilities are not a possible source as ground magnetometer data of CANOPUS and Greenland showed that the substorm had an eastward propagation, opposite to the wave propagation. KHI was a possible candidate for energizing the cavity/waveguide modes which drive the $1.1 \mathrm{mHz}$ large amplitude FLRs, as the negative $\mathrm{m}$ value indicates a wave source at the dawn flank and the high-speed solar wind stream is a favorable condition for exciting KHIs. However, we cannot exclude other possibilities.

As for the higher frequency $(>1.1 \mathrm{mHz})$ pulsations observed by Polar, Geotail and GOES 12, the source could be a wide band compressional wave coupling to standing waves almost everywhere as suggested by Hasegawa et al. (1983), as the wave packets at higher frequencies look different from that of $1.1 \mathrm{mHz}$. The change of wave properties at $\sim 06: 15$ UT and $\sim 06: 45$ UT at NAQ in Fig. 8 is coincident with the North-South-North turning of the IMF $B_{z}$ at the corresponding times. It seems that IMF has more direct control over the wave properties at higher frequencies.

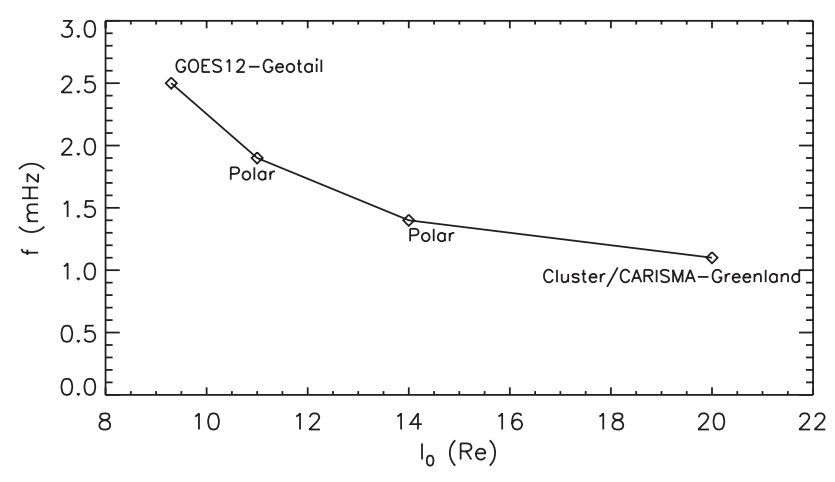

Fig. 16. The frequency $(f)$ versus 1 shell relationship based on the observations.

The unusually low frequency waves observed at Gillam latitude, such as the $1.3-\mathrm{mHz}$ FLR reported by Lotko et al. (1998), have caused some concern as the frequency cannot be explained using dipole field lines. This study not only shows that an even lower frequency FLR $(1.1 \mathrm{mHz})$ at Gillam is possible, but also provides an explanation for the unusually low frequency oscillations: Gillam can be located on very stretched field lines. It has been demonstrated 
theoretically that a stretched magnetic topology can explain anomalously low-frequency FLRs (Lui and Cheng, 2001; Wanliss et al., 2002). Wanliss et al. (2002) have shown theoretically that it requires $n_{H}=2 \mathrm{~cm}^{-3}$ with inclusion of oxygen (see the paper for details) in order to get $\mathrm{f}=1.4 \mathrm{mHz}$ at $l_{0}=13 R_{E}$. From the CODIF (Composition and Distribution Function) measurements of Cluster, the average density for all the measured species is: $n_{\mathrm{H}}=0.34 \mathrm{~cm}^{-3}, n_{\mathrm{O}}=0.031 \mathrm{~cm}^{-3}$, $n_{\mathrm{He}+}=0.003 \mathrm{~cm}^{-3}, n_{\mathrm{He}++}=0.036 \mathrm{~cm}^{-3}$. We can see that there was a substantial presence of $\mathrm{O}^{+}$and $\mathrm{He}^{++}$during the event, probably due to a Dst value of $-53 \mathrm{nT}$. This gives a mass density of $\sim 1 \mathrm{amucm}^{-3}$. Using the same mass density of $1 \mathrm{amucm}^{-3}$ (constant along magnetic field) and a self consistently calculated equilibrium magnetosphere, Lui and Cheng (2001) provided the FLR frequency for odd mode shear Alfvén waves at $l_{0}=19.9$, with the value being $2.46 \mathrm{mHz}$. Even though this value is higher than the $1.1 \mathrm{mHz}$ waves observed by Cluster, the non-uniform distribution of the plasma mass density along the field line and longer field line length $\left(l_{0}=21.2\right)$ at Cluster may help explain the lower frequency $(1.1 \mathrm{mHz})$ standing Alfvén wave at Cluster location. From comparisons with both theoretical results, we can see that stretched field line configuration is required to explain the "anomalously" low frequency oscillations at Cluster and Gillam. Mid-tail extremely low frequency oscillations (sometimes with a frequency even smaller than $1.1 \mathrm{mHz}$ ) have also been observed most noticeably in $\mathrm{V}_{\mathrm{y}}$ (GSM) polarization on other occasions (e.g. the $\sim 12$-min oscillation during 03:30-05:30 UT on 27 July 2001 and during 01:0003:00 UT on 13 August 2003; the 21-min oscillation taking place during 10:40-12:40 UT on 11 September 2002) when Cluster was in the tail plasma sheet region, suggesting Pc5/even lower frequency pulsations may be common on stretched field lines in the tail.

This study has important implications in that there may be other means beside the re-reconnection in the tail for the solar wind energy to be transferred to the magnetospheric system. KHI can produce a series of wave modes at all latitudes but the perturbations in the LLBL and subsequently in the plasma sheet are the most important ones as LLBLs are most unstable to KHI and the perturbations produced carry most of the energy and momentum. FLRs through coupling of the cavity/waveguide mode (which can be excited by KHI) to local shear Alfvén waves in the mid-tail plasma sheet region can be an important means for the solar wind energy to be transferred to the tail and subsequently affect the state of the magnetosphere and ionosphere system.

\section{Summary}

This study constitutes the first coordinated observation of a driven discrete FLR in the mid-magnetotail at a very low frequency $(1.1 \mathrm{mHz})$ by Cluster spacecraft in space and an array of magnetometer stations on the ground near Cluster's footpoint, which exhibits classical FLR features. Evidence of FLRs is further provided by simultaneous quasi-periodic oscillations observed by Polar, Geotail and GOES 12 that were located closer to Earth. The observed discrete frequency and L shell relation is in accord with FLR theory. This event shows that the magnetosphere was in oscillation over a large azimuthal extent, but over a narrow latitudinal range.

Acknowledgements. The authors thank both referees for helpful comments and thank the whole Cluster team for making it a success. GOES data were obtained from CDAWEB. We thank the CARISMA and Greenland magnetometer team for data, B. H. Mauk, R. W. McEntire, S. Ohtani, H. J. Singer for helpful discussions and J. Vernetti for helping with the SDT software. This work was supported by NSF grant ATM-0135667 to JHU/APL and by NASA grant NAG5-13119.

Topical Editor I. A. Daglis thanks P. A. Puhl-Quinn and A. V. Streltsov for their help in evaluating this paper.

\section{References}

Allan, W., White, S. P., and Poulter, E. M.: Impulse excited hydromagnetic cavity and field line resonances in the magnetosphere, Planet. Space Sci., 34, 371-385, 1986.

Allan W. and Wright, A. N.: Hydromagntic wave propagation and coupling in a magnetotail waveguide, J. Geophys. Res. 103(A2), 2359-2368, 1998.

Balogh, A., Carr, C. M., Acuña, M. H., Dunlop, M. W., Beek, T. J., Brown, P., Fornaçon, K.-H., Georgescu, E., Glassmeier, K.H., Harris, J., Musmann, G., Oddy, T., and Schwingerschuh, K.: The Cluster magnetic field investigation: Overview of in-flight performance and initial results, Ann. Geophys. 19, 1207-1217, 2001.

Chen, L. and Hasegawa, A.: A theory of long period magnetic pulsations, 1, Steady state excitation of field line resonance, J. Geophys. Res., 79, 1024-1032, 1974.

Dungey, D. W.: Electrodynamics of the outer atmosphere, Sci. Rep. 69, Penn. State Univ., University Park, 1954.

Fenrich, F. R., Samson, J. C., Sofko G., and Greenwald R. A.: ULF high- and low-m field line resonances observed with the Super Dual Auroral Radar Network, J. Geophys. Res., 100(A11), 21 535-21 548, doi:10.1029/95JA02024, 1995.

Glassmeier, K.-H., Othmer, C., Cramm, R., Stellmacher, M., and Engebretson, M.: Magnetospheric field line resonances: a comparative planetology approach, Surveys in Geophysics 20, 61109, 1999.

Gustafsson, G., Bostrom, R., Holback, B., et al.: The electric field and wave experiment for Cluster mission, Space Sci. Rev., 79(12), 137-156, 1997.

Hasegawa, A., Tsui, K. H., and Assis, A. S.: A theory of long period magnetic pulsations, 3. Local field line oscillations, Geophys. Res. Lett., 10, 765-767, 1983.

Keiling, A., Kim, K.-H., Wygant, J. R., Cattell, C., Russell, C. T., and Kletzing, C. A: Electrodynamics of a substorm-related field line resonance observed by the Polar satellite in comparison with ground Pi2 pulsations, J. Geophys. Res., 108(A7), 1275, doi:10.1029/2002JA009340, 2003. 
Kivelson, M. G. and Southwood, D. J.: Resonant ULF waves: A new interpretation, Geophys. Res. Lett., 49-52, 1985.

Kivelson, M. G. and Southwood, D. J.: Coupling of global magnetospheric MHD eigenmodes to field line resonances, J. Geophys. Res., 91(A4), 4345-4351, 1986.

Laakso, H., Fairfield, D. H., Russell, C. T., et al.: Field-line resonances triggered by a northward IMF turning, Geophys. Res. Lett., 25, 2991-2994, 1998.

Lee, D. H. and Lysak, R. L.: Magnetospheric ULF wave coupling in the dipole model: The impulsive excitation, J. Geophys. Res., 94, 17 097-17 103, 1989.

Lotko, W., Streltsov, A. V., and Carlson, C. W.: Discrete auroral arc, electrostatic shock and suprathermal electrons powered by dispersive, anomalously resistive field line resonances, Geophys. Res. Lett., 25, 4449-4452, 1998.

Lui, A. T. Y. and Murphree, J. S.: A substorm model with onset location tied to an auroral arc, Geophys. Res. Lett., 25, 12691273, 1998.

Lui, A. T. Y. and Cheng, C. Z.: Resonance frequency of stretched magnetic field lines based on a self-consistent equilibrium magnetosphere model, J. Geophys. Res., 106(A11), 25 793-25 802, 2001.

Mann, I. R., Chisham, G., and Bale, S. D.: Multisatellite and ground-based observations of a tailward propagating Pc5 magnetospheric waveguide mode, J. Geophys. Res., 103, 4657-4669, 1998.

Mann, I. R., Wright, A. N., Mills, K. J., and Nakariakov, V. M.: Excitation of magnetospheric waveguide modes by magnetosheath flows, J. Geophys. Res., 104 (A1), 333-353, 1999.

Mann, I. R., Voronkov, I., Dunlop, M., et al.: Coordinated groundbased and Cluster observations of large amplitude global magnetospheric oscillations during a fast solar wind interval, Ann. Geophys. 20, 405-426, 2002.

Mathie, R. A. and Mann, I. R.: On the solar wind control of Pc5 ULF pulsation power at mid-latitudes: Implications for $\mathrm{MeV}$ electron acceleration in the outer radiation belt, J. Geophys. Res., 106(A12), 19783-19796, 2001.

Ohtani, S., Rostoker, G., Takahashi, K., et al.: Coordinated ISTP satellite and ground observations of morningside Pc5 waves, J. Geophys. Res., 104, 2381-2397, 1999.

Rankin, R., Samson, J. C., and Frycz, P.: Simulations of driven field line resonances in the Earth's magnetosphere, J. Geophys. Res., 98 (A12), 21341-21352, 1993.

Rankin, R., Frycz, P., Tikhonchuk, V. T., et al.: Ponderomotive aturation of magnetospheric field line resonances, Geophys. Res. Lett., 22, 1741-1744, 1995 .

Rankin, R., Samson, J. C., and Tikhonchuk, V. T.: Discrete auroral arcs and nonlinear dispersive field line resonances, Geophys. Res. Lett., 26, 663-666, 1999.

Rème, H., Aoustin, C., Bosqued, J. M., et al.: First multispacecraft ion measurements in and near the Earth's magnetosphere with the identical Cluster Ion Spectrometry (CIS) experiment, Ann. Geophys. 19, 1303-1354, 2001.

Ruohoniemi, J. M., Greenwald, R. A., Baker, K. B., and Samson, J. C.: HF radar observations of Pc 5 field line resonances in the midnight/early morning MLT sector, J. Geophys. Res., 96, $15697-15710,1991$.
Samson, J. C., Jacobs, J. A., and Rostoker, G.: Latitude-dependent characteristics of long-period geomagnetic pulsations, J. Geophys. Res. 76, 3675-3683, 1971.

Samson, J. C., Hughes, T. J., Creutzberg, F., illis, D. D., Greenwald, R. A., and Ruohoniemi, J. M.: bservations of a detached discrete arc in association with field line resonances, J. Geophys. Res., 96, 15 683-15 695, 1991.

Samson, J. C., Harrold, B. G., Ruohoniemi, J. M., Greenwald, R. A., and Walker, A. D. M.: Field line resonances associated with MHD waveguides in the magnetosphere, Geophys. Res. Lett., 19, 441-444, 1992a.

Samson, J. C., Wallis, D. D., Hughes, T. J., Creutzberg, F., Ruohoniemi, J. M., and Greenwald, R. A.: Substorm intensification and field line resonances in the nightside magnetosphere, J. Geophys. Res., 97, 8459-8518, 1992b.

Singer, H. J., and Kivelson M. G.: The latitudinal structure of Pc5 waves in space: Magnetic and electric field observations, J. Geophys. Res., 84, 7213-7222, 1979.

Southwood, D. J.: Some features of field line resonances in the magnetosphere, Planet Space Sci., 22, 483-491, 1974.

Streltsov, A. and Lotko, W.: The fine structure of dispersive, nonradiative field line resonance layers, J. Geophys. Res. 101(A3), 5343-5358, 1996.

Streltsov, A. and Lotko, W.: Small scale "electrostatic" auroral tructures and Alfvén waves, J. Geophys. Res., 104, 4411-4426, 1999.

Takahashi, K., Anderson, B. J., and Ohtani, S.: Multisatellite study of nightside transient toroidal waves, J. Geophys. Res., 101, 24 815-24 825, 1996.

Takahashi, K.: ULF waves: 1997 IAGA Division 3 reporter review, Ann. Geophys. 16, 787-803, 1998.

Tsyganenko, N. A.: Modeling the Earth's magnetospheric magnetic field confined within a realistic magnetopause, J. Geophys. Res. 100, 5599-5612, 1995.

Tsyganenko, N. A. and Sitnov, M. I.: Modeling the dynamics of the inner magnetosphere during strong geomagnetic storms, J. Geophys. Res., 110, A03208, doi:10.1029/2004JA010798, 2005.

Walker, A. D. M., Ruohoniemi, J. M., Baker, K. B., Greenwald, R. A., and Samson, J. C.: Spatial and temporal behavior of ULF pulsations bserved by the Goose Bay HF radar, J. Geophys. Res., 97, 12 187-12 202, 1992.

Wanliss, J. A., Rankin, R., Samson, J. C., and Tikhonchuk, V. T.: Field line resonances in a stretched magnetotail: CANOPUS optical and magnetometer observations, J. Geophys. Res., 107(A7), 1100, doi:10.1029/2001JA000257, 2002.

Wright A. N.: Dispersion and wave coupling in inhomogeneous MHD wave-guides, J. Geophys. Res. 99(A1), 159-167, 1994.

Wright, A. N. and Allan, W.: Structure, phase motion and heating within Alfvén resonances, J. Geophys. Res., 101, 17 399-17408, 1996.

Ziesolleck, C. W. S. and McDiarmid, D. R.: Auroral latitude Pc5 field line resonance: Quantized frequencies, spatial characteristics, and diurnal variation, J. Geophys. Res., 99, 5817-5830, 1994. 